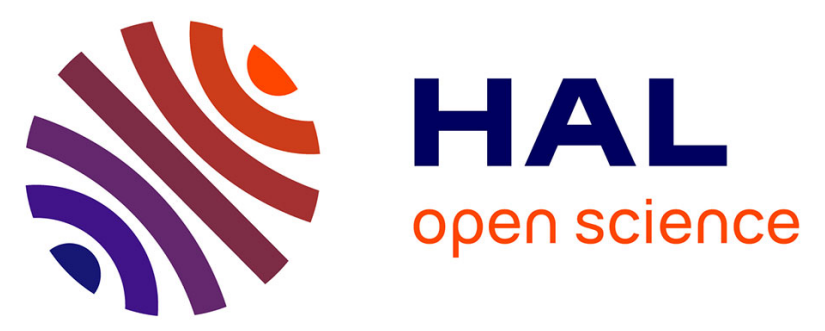

\title{
Efficient Electron Transfer and Sensitizer Regeneration in Stable $\pi$-Extended Tetrathiafulvalene-Sensitized Solar Cells
}

Sophie Wenger, Pierre-Antoine Bouit, Qianli Chen, Joël Teuscher, Davide Di Censo, Robin Humphry-Baker, Jaques-E. Moser, Juan Luis Delgado, Nazario Martin, Shaik M. Zakeeruddin, et al.

\section{To cite this version:}

Sophie Wenger, Pierre-Antoine Bouit, Qianli Chen, Joël Teuscher, Davide Di Censo, et al.. Efficient Electron Transfer and Sensitizer Regeneration in Stable $\pi$-Extended TetrathiafulvaleneSensitized Solar Cells. Journal of the American Chemical Society, 2010, 132 (14), pp.5164-5169. 10.1021/ja909291h . hal-01089797

\section{HAL Id: hal-01089797}

\section{https://hal-univ-rennes1.archives-ouvertes.fr/hal-01089797}

Submitted on 16 Mar 2017

HAL is a multi-disciplinary open access archive for the deposit and dissemination of scientific research documents, whether they are published or not. The documents may come from teaching and research institutions in France or abroad, or from public or private research centers.
L'archive ouverte pluridisciplinaire HAL, est destinée au dépôt et à la diffusion de documents scientifiques de niveau recherche, publiés ou non, émanant des établissements d'enseignement et de recherche français ou étrangers, des laboratoires publics ou privés. 


\section{Efficient Electron Transfer and Sensitizer Regeneration}

\section{in Stable $\pi$-Extended Tetrathiafulvalene-Sensitized Solar}

\section{Cells}

Sophie Wenger, ${ }^{a}$ Pierre-Antoine Bouit, ${ }^{b}$ Qianli Chen, ${ }^{a}$ Joël Teuscher, ${ }^{a}$ Davide Di Censo, ${ }^{a}$ Robin Humphry-Baker, ${ }^{a}$ Jaques-E. Moser, ${ }^{a}$ Juan Luis Delgado, ${ }^{b, c}$ Nazario Martín, ${ }^{b, c} *$ Shaik M. Zakeeruddin, ${ }^{a} *$ and Michael Grätzel ${ }^{a *}$

${ }^{a}$ Laboratory of Photonics and Interfaces, Institute of Chemical Sciences and Engineering, Ecole Polytechnique Fédérale de Lausanne (EPFL), Station 6, CH-1015 Lausanne, Switzerland

${ }^{\mathrm{b}}$ IMDEA-Nanociencia, Facultad de Ciencias, Módulo C-IX, $3^{\mathrm{a}}$ planta, Ciudad Universitaria de Cantoblanco, 28049 Madrid, Spain

`Departamento de Química Orgánica, Facultad de Química, Universidad Complutense, 28040 Madrid, Spain

*Corresponding authors: nazmar@quim.ucm.es, shaik.zakeer@epfl.ch, and michael.graetzel@epfl.ch

ABSTRACT. The development of metal-free organic sensitizers is a key issue in dye-sensitized solar cell research. We report successful photovoltaic conversion with a new class of stable tetrathiafulvalene derivatives, showing surprising electrochemical and kinetic properties. With time-resolved spectroscopy we could observe highly efficient regeneration of the photo-oxidized tetrathiafulvalene sensitizers, which were attached to a mesoporous $\mathrm{TiO}_{2}$ film, by a redox mediator in the pores (iodide/tri-iodide), even though the measured driving force for regeneration was only about $150 \mathrm{mV}$. This important proof- 
of-concept shows that sensitizers with a small driving force, i.e. the oxidation potential is separated from the redox potenial of mediator by as little as $150 \mathrm{mV}$, can operate functionally in dye-sensitized solar cells and eventually aid to reduce photovoltage losses due to poor energetic alignment of the materials.

KEYWORDS. Electron transfer, sensitizers, tetrathiafulvalene, dye-sensitized solar cells, time-resolved spectroscopy

\section{Introduction}

Dye-sensitized solar cells (DSCs) can convert solar radiation into electricity efficiently and costeffectively by means of a light-harvesting sensitizer anchored to a high surface area mesoporous semiconductor film. ${ }^{1,2}$ Record efficiencies of over $11 \%$ have been measured with ruthenium-complex sensitizers on laboratory scale devices, ${ }^{3-5}$ but the scarcity of $\mathrm{Ru}$ metal and intricate synthesis and purification steps might retard future large-scale power production by DSCs. Metal-free organic sensitizers however can be synthesized rather inexpensively, and their absorption properties can be easily tuned by suitable molecular design. Reports of new organic sensitizer designs and their performance in DSCs have been mushrooming in the past years, ${ }^{6}$ and promising device efficiencies of up to $9.8 \%$ have been demonstrated with a donor- $\pi$-acceptor system employing a triphenylamine donor, a binary $\pi$-conjugated spacer, and a cyanoacrylic acid acceptor. ${ }^{7}$

Here we investigate the photovoltaic potential of sensitizers with a tetrathiafulvalene derivative donor and a cyanoacrylic acid accpetor in DSCs. Tetrathiafulvalenes with extended $\pi$-conjugation (exTTF) are a well known class of electron donor systems. ${ }^{8,9}$ Several studies have investigated charge transfer events in exTTFs attached to fullerenes ${ }^{10-13}$ and to single-walled carbon nanotubes. ${ }^{14}$ The out-of-plane butterfly shape of the exTTF provides steric hindrance, ${ }^{9}$ preventing self-aggregation of the sensitizer, a significant parameter in the performance of DSCs. The exTTF sensitizer is attached to a mesoporous $\mathrm{TiO}_{2}$ film, to which it transfers an electron after photoexcitation. A surrounding redox mediator (iodide/tri-iodide couple) rapidly regenerates the oxidized sensitizer to prevent reduction by the injected 
electron. We provide a careful spectroscopic characterization and kinetic analysis of the formation of the oxidized sensitizer and its highly efficient regeneration by iodide, documenting for the first time efficient sensitizer reduction in DSCs with as little as $150 \mathrm{mV}$ driving force between the redox potential of the iodide/tri-iodide mediator and the oxidation potential of the sensitizer.

A series of three new exTTF sensitizers (PAB-1, PAB-2, and PAB-3, shown in Figure 1) was designed and synthesized in moderate yields by Knoevenagel condensation from the respective exTTFbased aldehydes. The sensitizers, which have in common the donor (exTTF) and acceptor/anchoring (cyanoacrylic acid) group, are differentiated by the extent of $\pi$-conjugation in the spacer. In PAB-3, an electron rich 3,4-ethylenedioxythiophene (EDOT) unit is used to considerably enhance its molar extinction coefficient. EDOT spacers have been successful to red shift the spectral response and enhance the molar extinction coefficient of triphenylamine donor sensitizers. ${ }^{7,15}$ In addition, we synthesized an analogue of PAB-3 with a TTF donor, coded PAB-4, to elucidate the conformational effect of a more planar molecule on self-aggregation and photovoltaic performance. As shown in the Supporting Information, absorbance spectra suggest aggregation on the $\mathrm{TiO}_{2}$ film, which might be responsible for the poor photovoltaic performance.
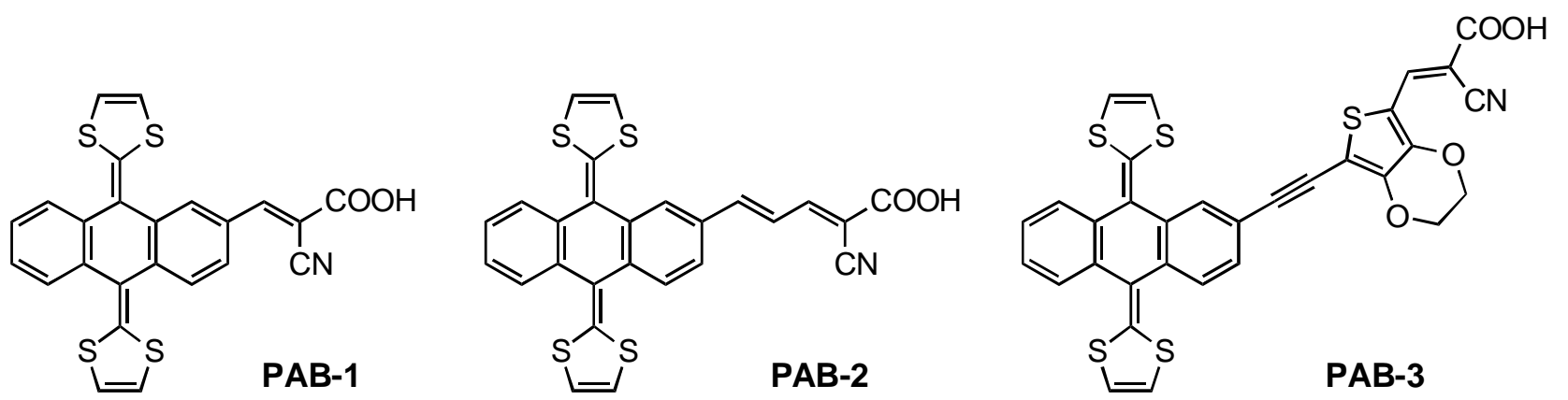

Figure 1. Molecular structures of functionalized exTTF sensitizers PAB-1, PAB-2, and PAB-3.

\section{Experimental Section}

Synthesis. Materials, synthesis of the sensitizers and full characterization are provided in the Supporting Information (SI). 
Electrochemical Measurements. Electrochemical data were obtained by cyclic and differential pulse voltammetry (CV and DPV) using a PC-controlled AutoLab system (PGSTAT-10, Eco Chimie). The electrochemical cell was assembled and measured in an Ar-filled glove-box. The glassy carbon disk working electrode (Metrohm), Pt-plate auxiliary electrode and Pt-wire quasi reference electrode were mounted in a single-compartment-cell configuration. Voltammograms of complexes were obtained by dissolving 0.5-1 mM of complex in DMF (anhydrous, 99.9\%) containing $0.1 \mathrm{M}$ tetrabutylammonium hexafluorophosphate as supporting electrolyte. After the measurement, ferrocene was added as internal reference for calibration of the other redox couple potentials versus the value relative to the ferrocenium/ferrocene couple.

ATR-FTIR Measurements. ATR-FTIR spectra were measured using a FTS 7000 FTIR spectrometer (Digilab, USA). The data were taken with a "Golden Gate" diamond anvil ATR accessory. Spectra were derived from 64 scans at a resolution of $2 \mathrm{~cm}^{-1}$. The samples were measured under the same mechanical force pushing the samples in contact with the diamond window. No ATR correction has been applied to the data. It has to be noted that this ATR technique probes at most $1 \mu \mathrm{m}$ of sample depth and that this depends on the sample refractive index, the porosity etc. Some of the spectra show artifacts due to attenuation of the light by the diamond window in the 2000 to $2350 \mathrm{~cm}^{-1}$ region. Dye-coated films were rinsed with acetonitrile and dried prior to measuring the spectra.

Device Fabrication. Dyes were tested in photovoltaic devices using standard mesoporous $\mathrm{TiO}_{2}$ films with a $5 \mu \mathrm{m}$ thick transparent layer of $20 \mathrm{~nm}$ sized particles on top of fluorine-doped tin oxide (FTO) coated glass. The detailed preparation procedures of the $\mathrm{TiO}_{2}$ nanoparticles and paste have been described elsewhere. ${ }^{16}$ Films were immersed for $5 \mathrm{~h}$ in a solution of $0.3 \mathrm{mM}$ dye and $10 \mathrm{mM}$ cheno in mixture of dimethyl sulfoxide (DMSO) and ethanol $(1 / 9, v / v)$. Cells were sealed with a platinized FTO counter electrode using a hot-melt (Surlyn, DuPont). Cells were then filled with an electrolyte through a hole in the counter electrode. The hole was then sealed with a Surlyn disc and a thin glass to avoid leakage of the electrolyte. We compared the photovoltaic performance using a volatile solvent-based electrolyte (coded as Z960) and an ionic liquid electrolyte (coded as Z952). The composition of 
electrolytes was as follows: Z960: $1.0 \mathrm{M}$ 1,3-dimethylimidazolium iodide, $0.03 \mathrm{M}$ iodine, $0.1 \mathrm{M}$ guanidinium thiocyanate, $0.5 \mathrm{M}$ tert-butylpyridine, $0.05 \mathrm{M} \mathrm{LiI}$ in a mixture of acetonitrile and valeronitrile (85/15, v/v). Z952: 1,3-dimethylimidazoliumiodide/1-ethyl-3-methylimidazoliumiodide/1ethyl-3methylimidazolium tetracyanoborate/iodine/N-butylbenzoimidazole/guanidinium thiocyanate (molar ratio 12/12/16/1.67/3.33/0.67). The photoanode was covered with a UV-cutoff/antireflecting polymer.

Photovoltaic Characterization and Stability Tests A $450 \mathrm{~W}$ xenon light source (Oriel, USA) was used to give an irradiance of $100 \mathrm{~mW} \mathrm{~cm}{ }^{-2}$ (the equivalent of one sun at air mass global, AM 1.5G, at the surface of solar cells). The spectral output of the lamp was matched in the region of 350-750 nm with the aid of a Schott K113 Tempax sunlight filter (Präzisions Glas \& Optik GmbH, Germany) to reduce the mismatch between the simulated and true solar spectra to less than $2 \%$. The current-voltage characteristics of the cell were obtained by applying an external potential bias to the cell and measuring the generated photocurrent with a Keithley model 2400 digital source meter (Keithley, USA). The effective area of the devices was defined with a metal mask to be $0.159 \mathrm{~cm}^{2}$.

A similar data acquisition system was used to control the incident photon to collected electron conversion efficiency (IPCE) measurement. Under computer control, light from a $300 \mathrm{~W}$ xenon lamp (ILC Technology, USA) was focused through a Gemini-180 double monochromator (Jobin Yvon Ltd., UK) onto the photovoltaic cell under test. A computer controlled monochromator was incremented through the spectral range $(300-900 \mathrm{~nm})$ to generate a photocurrent action spectrum with a sampling interval of $10 \mathrm{~nm}$ and a current sampling time of $5 \mathrm{~s}$.

For stability tests, devices were irradiated at open-cirucit under a Suntest CPS plus lamp (ATLAS

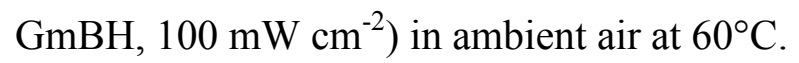

Transient photovoltage and photocurrent decay measurements Transient decays were measured with different white light steady-state biases and a superimposed red light perturbation pulse $(0.05 \mathrm{~s}$ square pulse width, $100 \mathrm{~ns}$ rise and fall time), incident on the photoanode side of the test device. The white and red light was supplied by light-emitting diodes. The voltage dynamics were recorded at open- 
circuit on a PC-interfaced Keithley 2400 source meter with a $500 \mu$ s response time. The perturbation light source was set to a suitably low level for the voltage decay kinetics to be monoexponential. By varying the white light bias intensity, the recombination rate constant could be estimated at open-circuit potentials of the device (corresponding to different free charge densities in the $\mathrm{TiO}_{2}$ film).

Nanosecond Laser Transient Absorbance Measurements $4.8 \mu \mathrm{m}$ thick transparent nanocrystalline anatase $\mathrm{TiO}_{2}$ films (16 nm particle diameter, porosity $\left.=0.625\right)$ were coated with PAB-1, PAB-2, or PAB-3 dye for $\sim 12$ hours. The samples were excited by pulses produced by a broad-band optical parametric oscillator (OPO GWU-355) pumped with a Continuum Powerlite 7030 frequency-tripled (i.e. $355 \mathrm{~nm}$ ) Q-switched Nd:YAG running at $30 \mathrm{~Hz}$. The output excitation wavelength was tuned at $\lambda=$ $505 \mathrm{~nm}$ with a pulse width of $7 \mathrm{~ns}$ (FWHM). Pulse energy was attenuated with neutral density grey filters down to $30 \mu \mathrm{J} \mathrm{cm}^{-2}$, a fluence under which our samples exhibit, on average, less than one injected electron per nanoparticle. The probe light was produced by a Xenon arc lamp. This light was filtered through a monochromator and diverse filters, focused onto the sample and then collected in a second monochromator. It was then detected by fast photomultiplier tube biased with $750 \mathrm{~V}$. Averaging over 1000 to 2000 laser shots was necessary to obtain satisfactory signal to noise ratios. Combination of several transients, recorded at different wavelengths permits to reconstruct a transient spectrum.

\section{Results and Discussion}

Electronic Absorption and Redox Behavior. The absorbance spectra of the sensitizers in dimethylsulfoxide and anchored to a transparent mesoporous $\mathrm{TiO}_{2}$ film are shown in Figure 2. The absorption peak of PAB-1 at $399 \mathrm{~nm}$ (extinction coefficient $\varepsilon=14.1 \times 10^{3} \mathrm{M}^{-1} \mathrm{~cm}^{-1}$ ), PAB-2 at $411 \mathrm{~nm}$ $\left(\varepsilon=25.1 \times 10^{3} \mathrm{M}^{-1} \mathrm{~cm}^{-1}\right)$, and PAB-3 at $419 \mathrm{~nm}\left(\varepsilon=36.0 \times 10^{3} \mathrm{M}^{-1} \mathrm{~cm}^{-1}\right)$ are attributed to $\pi-\pi^{*}$ charge transfer transitions in the exTTF chromophores. The gradual increase in $\varepsilon$ and the slightly red-shifted absorbance peaks are due to the extended $\pi$-conjugation in the spacer. In sensitized $\mathrm{TiO}_{2}$ films we observe a small red-shift of the peak for PAB-1 (414 nm) and PAB-2 (416 nm) and a blue-shift for 
PAB-3 (404 nm), which is attributed to the coupling of the carboxylate moiety with the semiconductor. Notably, blue-shift have been previously observed with organic sensitizers containing an EDOT spacer. ${ }^{15}$ The concentration of dye molecules adsorbed on the $\mathrm{TiO}_{2}$ film was estimated by desorbing sensitized films with tetrabutylammonium hydroxide in N,N'-dimethylformamide solution. A similar dye loading was obtained for PAB-1 and PAB-2 $(\mathrm{c}=0.13 \mathrm{M})$, and a slightly better packing behavior on the $\mathrm{TiO}_{2}$ surface was seen for PAB-3 $(\mathrm{c}=0.16 \mathrm{M})$.

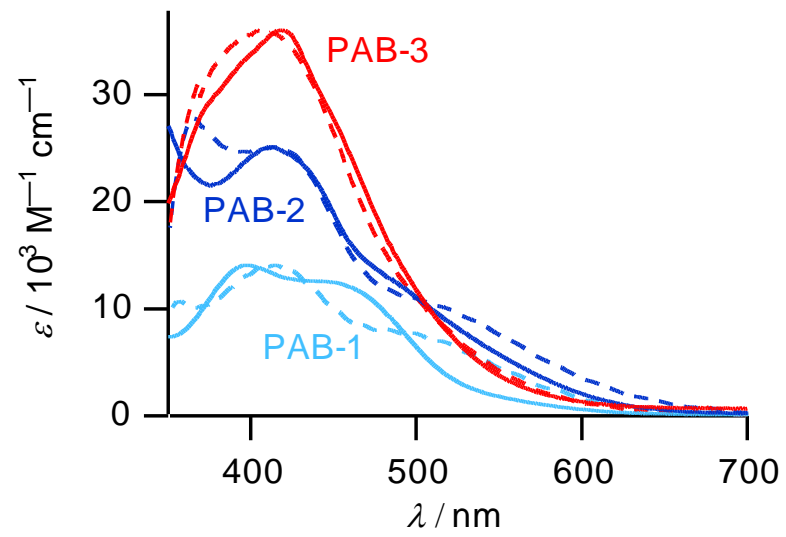

Figure 2. Molar extinction coefficient $(\varepsilon)$ of PAB-1, PAB-2, and PAB-3, in dimethylsulfoxide (bold lines). Dashed lines show the absorbance of the sensitizers attached to a transparent $\mathrm{TiO}_{2}$ film, normalized to the respective peak values in solution. The blank $\mathrm{TiO}_{2}$ film was subtracted from the measurement for clarity of presentation.

The electrochemical oxidation of the exTTF chromophore was previously reported as an overall twoelectron process ${ }^{17-19}$ occurring with potential inversion, i.e. the second electron is removed more easily than the first. The extent of potential inversion is estimated to be about $0.16 \mathrm{~V}$ from simulations of cyclic voltammograms. ${ }^{20}$ Formation of the short-lived radical cation and its disproportionation into the stable dication has been studied with radiolytic oxidation ${ }^{21}$ and flash photolysis techniques. ${ }^{21,22}$

The electrochemical properties of the sensitizers were assessed with differential pulse and cyclic voltammetry in dimethylformamide (DMF) solution using tetrabutylammonium hexafluorophosphate $\left(\mathrm{TBAPF}_{6}\right)$ as a supporting electrolyte and referenced to the ferrocinium/ferrocene $\left(\mathrm{Fc}^{+} / \mathrm{Fc}\right)$ couple. 
Interestingly, the two-electron oxidation potential $\left(E_{o x}\right)$ of the compounds (Figure 3 and Table 1), indicating the highest occupied molecular orbital (HOMO), is up to $300 \mathrm{mV}$ more negative than $E_{o x}$ of a standard Ru-complex sensitizer $\left(+0.16 \mathrm{~V}\right.$ vs. $\left.\mathrm{Fc}^{+} / \mathrm{Fc}\right) .{ }^{16}$ The one-electron oxidation potential $(\mathbf{P A B}-1 \rightarrow$ PAB-1 ${ }^{++}$) is estimated to be $80 \mathrm{mV}$ more positive due to potential inversion. ${ }^{20}$ Consequently, the driving force for regeneration of the oxidized species by the $\mathrm{I}^{-} / \mathrm{I}_{3}{ }^{-}$redox mediator $\left(-0.21 \mathrm{~V} \mathrm{vs} . \mathrm{Fc}^{+} / \mathrm{Fc}\right.$ in ionic liquid) $)^{23}$ is as low as $150 \mathrm{mV}$. We note that the $\mathrm{Fc}^{+} / \mathrm{Fc}$ couple is a suitable reference for these compounds, since their $E_{o x}$ peak is well distinguished from the reference peak (Figure S1). The reduction potential $\left(E_{\text {red }}\right)$ of the dyes, indicating their lowest unoccupied molecular orbital (LUMO), is considerably more negative than the $\mathrm{TiO}_{2}$ conduction band, providing ample driving force for electron transfer.

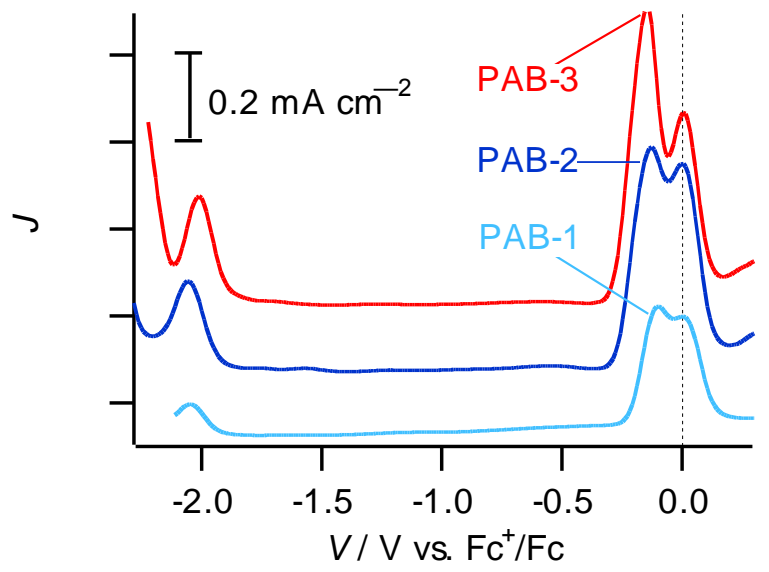

Figure 3. Differential pulse voltammograms of PAB-1, PAB-2, and PAB-3 with ferrocene in DMF using 0.1 $\mathrm{M} \mathrm{TBAPF}_{6}$ as a supporting electrolyte. Working electrode: glassy carbon disk, $0.07 \mathrm{~cm}^{2}$.

Table 1. Oxidation and reduction potentials vs. $\mathrm{Fc}^{+} / \mathrm{Fc}$ and estimated HOMO-LUMO gap $\left(E_{g}\right)$ of PAB1, PAB-2, and PAB-3 determined from differential pulse voltammetry.

\begin{tabular}{llll}
\hline Dye & $E_{o x}(\mathrm{~V})$ & $E_{\text {red }}(\mathrm{V})$ & $E_{g}(\mathrm{eV})$ \\
\hline PAB-1 & -0.11 & -2.05 & 1.94 \\
PAB-2 & -0.12 & -2.06 & 1.94 \\
PAB-3 & -0.14 & -2.01 & 1.87 \\
\hline
\end{tabular}


Density functional theory (DFT) calculations were performed with the Spartan software package using the B3LYP hybrid functional and the $6-31^{*} \mathrm{G}$ basis set to investigate the electronic properties of the sensitizers. The orbital energy levels in vacuum, minimum energy conformations, and electron density plots are shown in Figure S2. The well-known structure of the neutral state is saddle-shaped. ${ }^{19,24}$ The HOMO of PAB-1 and PAB-2 are at a similar energy level, whereas the HOMO of PAB-3 is raised due to the high electron density in the EDOT spacer. The LUMO of PAB-2 and PAB-3 are lower than the LUMO of PAB-1 due to extended $\pi$-conjugation in the spacer. In all three cases, the HOMO is delocalized over the anthracene and dithiole units, and the LUMO is delocalized over the cyanoacrylic acid group, facilitating electron transfer from the excited state to the $\mathrm{TiO}_{2}$ conduction band via the carboxylate anchoring group.

ATR-FITR Spectra. The ATR-FTIR spectra of the sensitizers in powder form and anchored on a mesoporous $\mathrm{TiO}_{2}$ film shown in Figure S3. The powder spectra show a distinct band at $1700 \mathrm{~cm}^{-1}$ for the $\mathrm{C}=0$ stretch in the carboxyl group. This band is not observed in the spectra of the sensitized films. Instead, the spectra clearly show bands at $1630 \mathrm{~cm}^{-1}$ and $1385 \mathrm{~cm}^{-1}$ for the asymmetric and symmetric stretching modes of the carboxylate groups, indicating that the carboxylic acid is deprotonated and involved in the adsorption of the dye on the $\mathrm{TiO}_{2}$ surface.

Photovoltaic Performance The photovoltaic performance of the sensitizers, i.e. the incident photonto-current conversion efficiency (IPCE) and the photocurrent-voltage $(J-V)$ curve, was assessed in test devices using standard mesoporous $5 \mu \mathrm{m}$ thick $\mathrm{TiO}_{2}$ films and a volatile acetonitrile-based electrolyte. The device fabrication and electrolyte composition is described in the SI. The IPCE in Figure 4a shows peak values of $48 \%$ at $510 \mathrm{~nm}$ for PAB-1, 54\% at $520 \mathrm{~nm}$ for PAB-2, and $72 \%$ at $460 \mathrm{~nm}$ for PAB-3 in accordance with the shape and magnitude of the respective extinction coefficients. From an estimation of the fraction of absorbed photons in the $\mathrm{TiO}_{2}$ film (using the Lambert-Beer law), we find that between $87 \%$ (PAB-1) and close to $100 \%$ (PAB-3) of the incident light absorbed in the $\mathrm{TiO}_{2}$ film at the respective absorption peak wavelength. Accounting for about $10 \%$ total reflection and absorbance losses in the fluorine-doped tin oxide front electrode, this implies an up to $30 \%$ higher fraction of absorbed 
photons than measured IPCE. We assume injection efficiency close to unity of photoexcited electrons into the $\mathrm{TiO}_{2}$ conduction band, due to the large offset between the LUMO of the dyes and the conduction band. Consequently, the low absorbed photon-to-current efficiency (APCE) suggests that a substantial fraction of electrons is lost during transport through the $\mathrm{TiO}_{2}$ film via recombination with triiodide and possibly with the sensitizer radical cation or even the dication at the $\mathrm{TiO}_{2} /$ dye/electrolyte interface.

The $J-V$ curves of devices with volatile electrolyte under simulated full sunlight (AM 1.5G, $100 \mathrm{~mW}$ $\mathrm{cm}^{-2}$ ) are shown in Figure $4 \mathrm{~b}$ and corresponding photovoltaic parameters, i.e. the conversion efficiency $(\eta)$, short-circuit photocurrent density $\left(J_{s c}\right)$, open-circuit photovoltage $\left(V_{o c}\right)$, and the fill factor $(F F)$, are given in Table 2. The increase in efficiency from 2.9\% (PAB-1) to 3.8\% (PAB-3) is largely due to an increase in photocurrent, in agreement with the measured IPCEs, and an associated small increase in photovoltage. Overall, the measured photovoltage is relatively low. With state-of-the-art DSCs one can expect a $V_{o c}$ of over $750 \mathrm{mV}$ at comparable current densities. ${ }^{5}$ This is a further indication for substantial charge recombination losses.

Table 2. Photovoltaic parameters of devices with a $5 \mu \mathrm{m}$ thick $\mathrm{TiO}_{2}$ film and volatile electrolyte under simulated AM 1.5G illumination $\left(100 \mathrm{~mW} \mathrm{~cm}^{-2}\right)$.

\begin{tabular}{lllll}
\hline Dye & $\begin{array}{l}\text { Efficiency } \\
(\%)\end{array}$ & $\begin{array}{l}V_{o c} \\
(\mathrm{mV})\end{array}$ & $\begin{array}{l}J_{s c} \\
\left(\mathrm{~mA} \mathrm{~cm}^{-2}\right)\end{array}$ & $\begin{array}{l}\text { FF } \\
(-)\end{array}$ \\
\hline PAB-1 & 2.9 & 555 & -7.2 & 0.72 \\
PAB-2 & 3.2 & 578 & -7.7 & 0.73 \\
PAB-3 & 3.8 & 579 & -8.6 & 0.76 \\
\hline
\end{tabular}




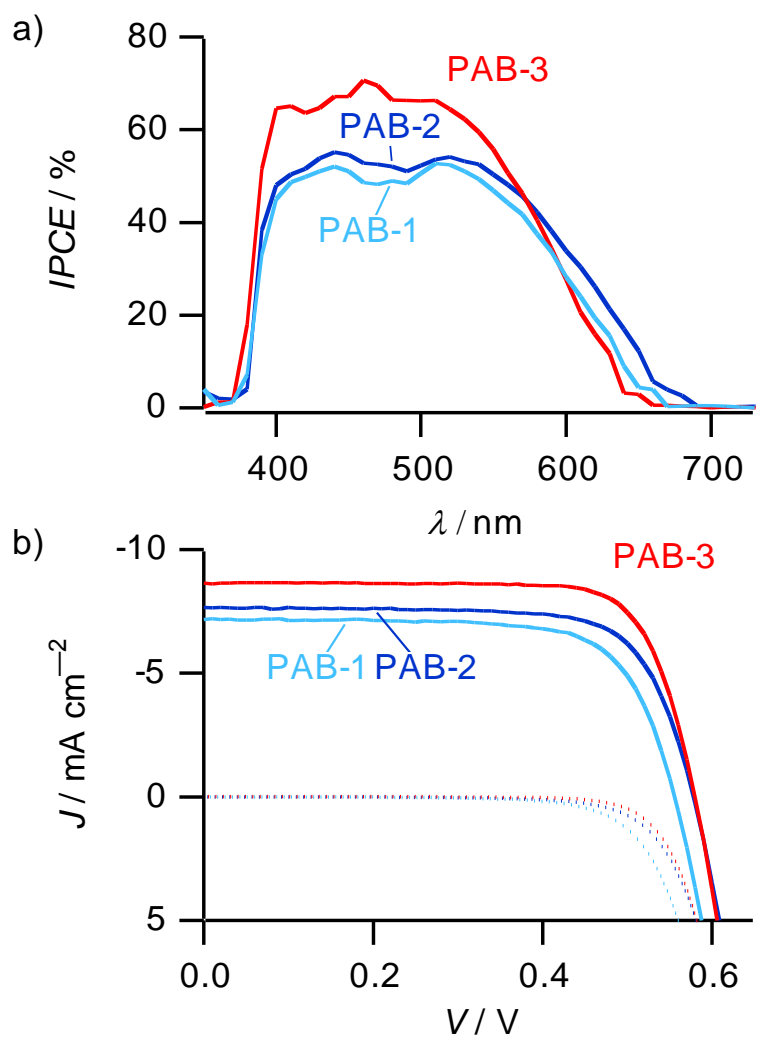

Figure 4. IPCE (a) and photocurrent-voltage curves (b) of test devices with $5 \mu \mathrm{m}$ thick $\mathrm{TiO}_{2}$ films, sensitized with PAB-1, PAB-2, or PAB-3, and volatile electrolyte under full $100 \mathrm{~mW} \mathrm{~cm}^{-2}$ AM $1.5 \mathrm{G}$ sunlight (continuous lines,) and in the dark (dotted lines).

Photovoltage Decay Transients We measured the photovoltage decay transients of devices with the volatile electrolyte at various white light bias intensities to study the charge recombination rates $\left(k_{e}\right)$ between electrons in the $\mathrm{TiO}_{2}$ conduction band and tri-iodide ions in the electrolyte. ${ }^{25}$ In Figure $5, k_{e}$ is plotted versus the open-circuit potential $\left(V_{o c}\right)$ induced by the white light bias. We note that the electron lifetime $\tau_{e}=k_{e}^{-1}$ is in the ms range. Since the $V_{o c}$ in the device is given by the difference between the redox level of the electrolyte and the quasi-Fermi level in the $\mathrm{TiO}_{2}$, which is determined by the concentration of free charge carriers, this plot allows us to compare $k_{e}$ at equal charge density concentrations in the $\mathrm{TiO}_{2}$ film. $k_{e}$ is known to increase exponentially with increasing bias light due to the filling of intraband trap states in the $\mathrm{TiO}_{2}$, which allows for a faster detrapping of electrons to the conduction band and subsequent recombination with tri-iodide. ${ }^{26}$ We measured a gradually decreased $k_{e}$ 
with increased spacer distance in the sensitizers, i.e. the highest $k_{e}$ with PAB-1 and an about 2.6 times reduced rate with PAB-3, which we attribute to the improved dye packing on the surface. However, $k_{e}$ of the device with PAB-3 is still two orders of magnitude higher than the rate of a state-of-the-art device with a ruthenium-complex dye. ${ }^{5}$ Increased recombination, and consequently low $V_{o c}$, have been observed for many classes of organic sensitizers and might be catalyzed by the formation of an iodine/dye complex. ${ }^{27}$

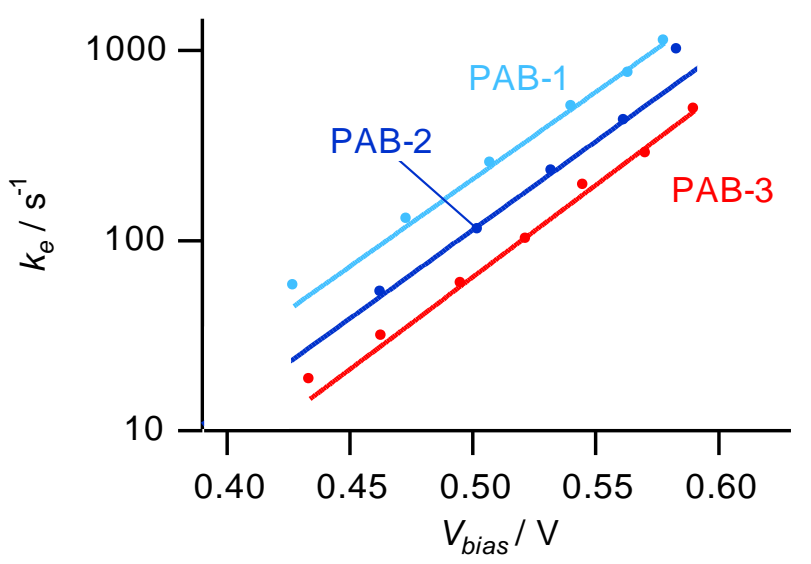

Figure 5. Recombination rate $k_{e}$ of $\mathrm{TiO}_{2}$ conduction band electrons with tri-iodide in devices with PAB1, PAB-2, or PAB-3, derived from photovoltage transients at various white light bias intensities. Lines are exponential fits to data.

Nanosecond Laser Transient Absorbance Measurements We used time-resolved spectroscopy on sensitized $\mathrm{TiO}_{2}$ films to probe the formation of the radical cation (1), its interception by iodide (2), and a possible disproportionation of the radical cation into the dication (3). The oxidation of the nonfunctionalized exTTF chromophore is well known; the short-lived radical cation $(\sim 500 \mu \mathrm{s})$ shows a fingerprint at about $650 \mathrm{~nm}$ and rapidly disproportionates into the stable dication. ${ }^{21,22}$

$$
\begin{aligned}
& \mathrm{S}^{*} \rightarrow \mathrm{S}^{\bullet+}+\mathrm{e}_{\mathrm{cb}}^{-} \\
& \mathrm{S}^{\bullet+}+2 \mathrm{I}^{-} \rightarrow \mathrm{S}+\mathrm{I}_{2}^{\bullet-} \text { and } 2 \mathrm{I}_{2}^{\bullet-} \rightarrow \mathrm{I}_{3}^{-}+\mathrm{I}^{-} \\
& \mathrm{S}^{\bullet+}+\mathrm{S}^{\bullet+} \rightarrow \mathrm{S}^{2+}+\mathrm{S} \\
& \mathrm{S}^{\bullet+}+\mathrm{e}_{\mathrm{cb}}^{-} \rightarrow \mathrm{S}
\end{aligned}
$$


The transient absorption spectrum of a PAB-1 sensitized film in Figure 6a (no redox mediator) clearly shows the signature of the radical cation at $650 \mathrm{~nm}$. The time-dependent signature at $650 \mathrm{~nm}$ of films sensitized with PAB-1, PAB-2, or PAB-3 is depicted in Figure 6b. In the absence of a redox mediator (only acetonitrile, $\mathrm{ACN}$ ), the decay can be fitted with a mono-exponential function with a time constant of $\tau=2.3 \mathrm{~ms}\left(k_{b}=435 \mathrm{~s}^{-1}\right)$ for PAB-1, $\tau=256 \mu$ s for PAB-2, and $\tau=494 \mu \mathrm{s}$ for PAB-3, reflecting the lifetime of the radical dye cation when reduced only by electrons from the $\mathrm{TiO}_{2}$ conduction band (4). In the presence of a redox mediator (ACN-based redox electrolyte), the decay is accelerated by two to three orders of magnitude $\left(\tau=7.4 \mu \mathrm{s}, k_{r}=1.35 \times 10^{5} \mathrm{~s}^{-1}\right.$ for PAB-1, $\tau=18 \mu \mathrm{s}$ for PAB-2, $\tau=25 \mu \mathrm{s}$ for PAB-3) due to rapid interception of the cation by iodide (2). These timescales are similar to values reported for Ru-based sensitizers. ${ }^{28}$ The dye regeneration yield by iodide, given by the $k_{r} /\left(k_{b}+k_{r}\right)$ ratio, exceeds 99\% for PAB-1 and 93\% for PAB-3. This finding is remarkable, as it shows, that a very small driving force of about $150 \mathrm{mV}$ between the redox potential of the electrolyte and the oxidation potential of the sensitizer is sufficient for efficient regeneration of the cation. The transient signature of PAB-1 at $550 \mathrm{~nm}$ in ACN only (Figure 6c) shows an initial bleaching of the ground state after charge injection. Recovery of the dye absorption takes place with a half reaction time of $\tau=55 \mu$ s. The positive signal observed $>50 \mu$ s after the laser pulse excitation is attributed to the dication absorption. The kinetic process is thus likely to be due to the dye cation disproportionation (3). In the presence of the electrolyte, this positive absorbance disappears completely, and only a fast recovery of the ground state is observed with $\tau=4.6 \mu$ s (the rapid component of a double-exponential fit), corresponding to the kinetics of the reduction of dye cations by iodide observed in the red spectral region. Consequently, little dication species should be formed in a working cell under full sunlight illumination. 

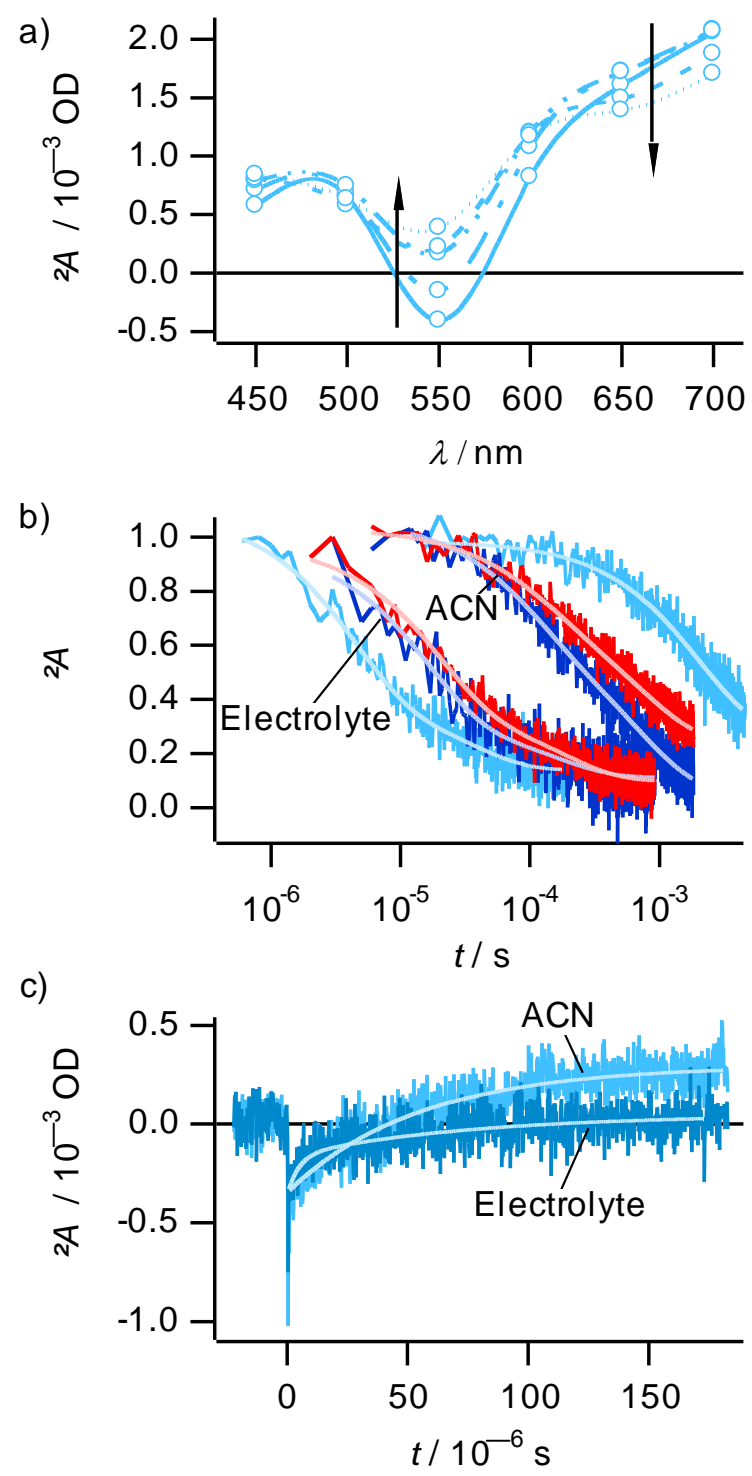

Figure 6. Temporal evolution of the transient absorption spectrum of a PAB-1 sensitized $\mathrm{TiO}_{2}$ film in acetonitrile $(\mathrm{ACN})$, showing the decay of the radical cation signature at $650 \mathrm{~nm}$ and the formation of the dication signal at $550 \mathrm{~nm}$ (bold line $10 \mu \mathrm{s}$ and dotted line $180 \mu \mathrm{s}$ after excitation). b) Normalized transient absorption decay at $650 \mathrm{~nm}$ of the radical cation of PAB-1 (light blue), PAB-2 (blue), or PAB3 (red) in ACN and in the presence of an iodide/tri-iodide redox electrolyte. Continuous lines drawn on top of experimental data are single exponential fits with the following time constants: In ACN: $\tau=2.3$ ms (PAB-1), $\tau=256 \mu$ s (PAB-2), $\tau=494 \mu$ s (PAB-3). In electrolyte: $\tau=7 \mu$ s (PAB-1), $\tau=18 \mu \mathrm{s}$ (PAB-2), $\tau=25 \mu$ s (PAB-3). c) Transient absorption at $550 \mathrm{~nm}$ of the dication of PAB-1 in ACN $(\tau=$ 
$55 \mu \mathrm{s})$ and in electrolyte $(\tau=5 \mu \mathrm{s}$, rapid part of a double-exponential fit). Absorbance changes were measured using $505 \mathrm{~nm}$ laser excitation (7 ns FWHM pulse duration, $30 \mu \mathrm{J} \mathrm{cm}^{-2}$ pulse fluence).

Device Stability We finally tested the long-term stability of the most promising PAB-3 sensitizer in devices with a solvent free ionic liquid electrolyte (composition given in the SI) during $1000 \mathrm{~h}$ of full sunlight illumination (AM $1.5 \mathrm{G}, 100 \mathrm{~mW} \mathrm{~cm}^{-2}$ ) at $60^{\circ} \mathrm{C}$. The evolution of the photovoltaic parameters is shown in Figure 7. Parameters are normalized to the stabilized values after 5 days of light soaking, which allowed for optimal reorganization of the dye molecules on the $\mathrm{TiO}_{2}$ surface. The device shows excellent stability, retaining $99 \%$ its initial efficiency.

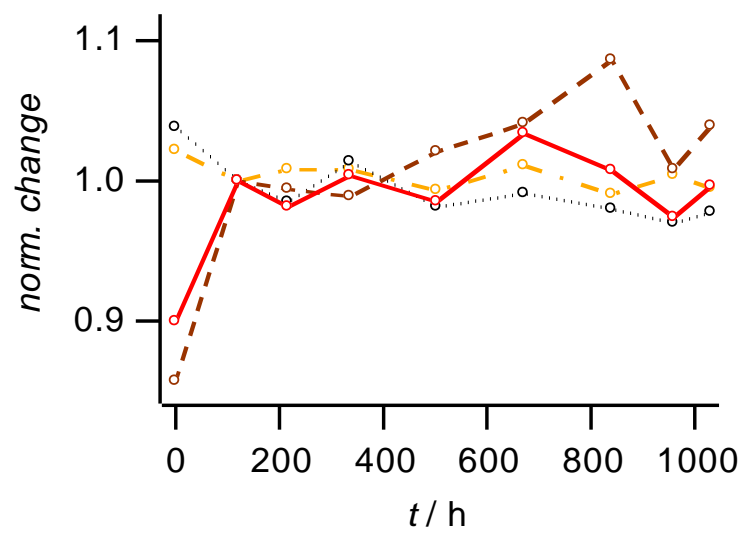

Figure 7. Photovoltaic parameters of a device with PAB-3 using ionic liquid after 1000 h of stability testing (full sunlight, $60^{\circ} \mathrm{C}$ ): $\eta$ (red bold line), $J_{s c}$ (brown dashed line), $V_{o c}$ (black dotted line), and $F F$ (orange, $-\bullet-)$. Parameters are normalized to stabilized values after $120 \mathrm{~h}$ of light soaking $\left(\eta=2.7 \%, J_{s c}\right.$ $\left.=-6.8 \mathrm{~mA} \mathrm{~cm}^{-2}, V_{o c}=534 \mathrm{mV}, F F=0.74\right)$.

\section{Conclusions}

We have successfully demonstrated photovoltaic energy conversion in stable $\pi$-extended tetrathiafulvalene-sensitized solar cells. Compared to standard ruthenium-complex sensitizers, these new dyes show an up to $300 \mathrm{mV}$ more negative oxidation potential, which could impair efficient reduction by the redox mediator. With time-resolved spectroscopy, however, we could prove for the first time that efficient regeneration of sensitizers with as little $150 \mathrm{mV}$ driving force between the 
oxidation potential of the sensitizer and the redox potential of the mediator is possible. Since large driving forces imply a loss in photovoltage, this finding provides a valuable proof-of-principle for the use and design of efficient sensitizers with low regeneration driving force for high efficiency dyesensitized solar cells.

Acknowledgments. This work was supported by the Swiss National Science Foundation (project NF 20020-125163/1), the European Science Foundation (05-SONS-FP-021 SOHYD), the MEC of Spain (CT2008-00795/BQU, and Consolider-Ingenio 2010C-07-25200, Nanociencia Molecular), and the Comunidad de Madrid (P-PPQ-000225-0505). JLD thanks the MICINN for a Ramón y Cajal Fellowship, co-financed by the EU Social Funds. We thank Pascal Comte, EPFL, for $\mathrm{TiO}_{2}$ film preparation and Dr. Carole Grätzel for fruitful discussions.

Supporting Information Available. Synthesis methods and characterization, supplementary voltammetric results, calculated molecular orbital levels, and ATR-FTIR spectra.

\section{References}

(1) O'Regan, B.; Grätzel, M. Nature 1991, 353, 737.

(2) Grätzel, M. Nature 2001, 414, 338.

(3) Nazeeruddin, M. K.; DeAngelis, F.; Fantacci, S.; Selloni, A.; Viscardi, G.; Liska, P.; Ito, S.; Takeru, B.; Grätzel, M. J. Am. Chem. Soc. 2005, 127, 16835.

(4) Chiba, Y.; Islam, A.; Watanabe, Y.; Komiya, R.; Koide, N.; Han, L. Jpn. J. Appl. Phys., Part 2 2006, 45 .

(5) (a) Gao, F.; Wang, Y.; Shi, D.; Zhang, J.; Wang, M. K.; Jing, X. Y.; Humphry-Baker, R.; Wang, P.; Zakeeruddin, S. M.; Grätzel, M. J. Am. Chem. Soc. 2008, 130, 10720. (b) Cao, Y; Bai, Y; Yu, Q; Cheng, Y; Liu, S; Shi, D; Gao, F; Wang, P; J. Phys. Chem. C 2009, 113, 6290. (c) Chen, CY.; Wang, M.; Li, J.-Y.; Pootrakulchote, N.; Alibabaei, L; Ngoc-le, C.-H.; Decoppet, J.-D.; Tsai, J.-H.; Grätzel, C.; Wu, C.-G.; Zakeeruddin, S. M.; Grätzel, M. ACS Nano, 2009, 3, 3103

(6) Mishra, A.; Fischer, M. K. R.; Bäuerle, P. Angew. Chem. Int. Ed. 2009, 48, 2474.

(7) Zhang, G.; Bala, H.; Cheng, Y.; Shi, D.; Lv, X.; Yu, Q.; Wang, P. Chem. Commun. 2009, 2198. 
(8) Segura, J. L.; Martín, N. Angew. Chem. Int. Ed. 2001, 40, 1372.

(9) Martín, N.; Sánchez, L.; Herranz, M. a. Á.; Illescas, B.; Guldi, D. M. Acc. Chem. Res. 2007, 40, 1015.

(10) Segura, J. L.; Priego, E. M.; Martín, N.; Luo, C.; Guldi, D. M. Org. Lett. 2000, 2, 4021.

(11) Herranz, M. A.; Martín, N.; Ramey, J.; Guldi, D. M. Chem. Commun. 2002, 2968.

(12) Sánchez, L.; Pérez, I.; Martín, N.; Guldi, D. M. Chem. Eur. J. 2003, 9, 2457.

(13) Giacalone, F.; Segura, J. L.; Martín, N.; Ramey, J.; Guldi, D. M. Chem. Eur. J. 2005, 11, 4819.

(14) Herranz, M. A.; Martín, N.; Campidelli, S. P.; Prato, M.; Brehm, G.; Guldi, D. M. Angew. Chem. Int. Ed. 2006, 45, 4478.

(15) Xu, M. F.; Wenger, S.; Bala, H.; Shi, D.; Li, R. Z.; Zhou, Y. Z.; Zakeeruddin, S. M.; Grätzel, M.; Wang, P. J. Phys. Chem. C 2009, 113, 2966.

(16) Wang, P.; Zakeeruddin, S. M.; Moser, J.-E.; Grätzel, M. J. Phys. Chem. B 2003, 107, 13280.

(17) Yamashita, Y.; Kobayashi, Y.; Miyashi, T. Angew. Chem. Int. Ed. 1989, 28, 1052.

(18) Moore, A. J.; Bryce, M. R. J. Chem. Soc. Perkin Trans. 1 1991, 1, 157.

(19) Martín, N.; Sánchez, L.; Seoane, C. J. Org. Chem. 1998, 63, 1268.

(20) Díaz, M. C.; Illescas, B. M.; Martín, N.; Perepichka, I. F.; Bryce, M. R.; Levillain, E.; Viruela, R.; Ortí, E. Chem. Eur. J. 2006, 12, 2709.

(21) Guldi, D. M.; Sánchez, L.; Martín, N. J. Phys. Chem. B 2001, 105, 7139.

(22) Jones, A. E.; Christensen, C. A.; Perepichka, D. F.; Batsanov, A. S.; Beeby, A.; Low, P. J.; Bryce, M. R.; Parker, A. W. Chem. Eur. J. 2001, 7, 973.

(23) Kawano, R.; Watanabe, M. Chem. Commun. 2003, 330.

(24) Bryce, M. R.; Moore, A. J.; Hasan, M.; Ashwell, G. J.; Fraser, A. T.; Clegg, W.; Hursthouse, M. B.; Karaulov, A. I. Angew. Chem. Int. Ed. 1990, 29, 1450.

(25) Duffy, N. W.; Peter, L. M.; Wijayantha, K. G. U. Electrochem. Commun. 2000, 2, 262.

(26) Bisquert, J.; Vikhrenko, V. S. J. Phys. Chem. B 2004, 108, 2313.

(27) O'Regan, B. C.; López-Duarte, I.; Martínez-Díaz, M. V.; Forneli, A.; Albero, J.; Morandeira, A.; Palomares, E.; Torres, T.; Durrant, J. R. J. Am. Chem. Soc. 2008, 130, 2906.

(28) Kuang, D. B.; Ito, S.; Wenger, B.; Klein, C.; Moser, J. E.; Humphry-Baker, R.; Zakeeruddin, S. M.; Grätzel, M. J. Am. Chem. Soc. 2006, 128, 4146. 
Table of Contents Graphic

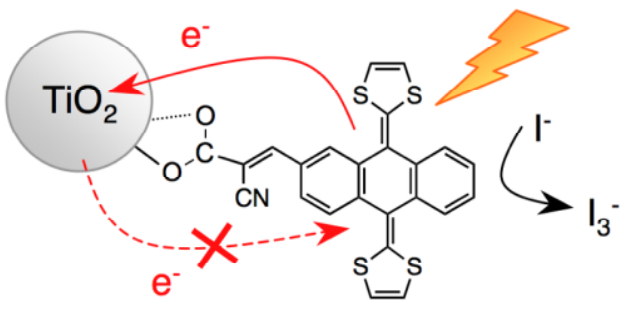

